\title{
Distributed architecture for a supply chain by integrating a multi- agent approach using simulation
}

\section{Arquitectura distribuida para una cadena de suministro integrando un enfoque multiagente mediante simulación}

\author{
Oscar Rubiano-Ovalle+1|⿴囗十) and José I. García-Melo*21 \\ + Grupo de Investigación en Logística y Producción \\ Universidad del Valle, Cali, Colombia
}

\begin{abstract}
This study proposes an architecture based on multiple agents through a Colored Petri Net model (CPN), which enables the integration of supply chain links and information technology to speed up the production process and services. The methodology was developed based on three fundamental concepts: CPN as design tool, Supply Chain (SC) Architecture and Multi-Agent Systems (MAS). As a case study, a typical supply chain in the Colombian production system was considered. As a case study, a typical supply chain in the Colombian production system was considered. For this, the study developed a modeling procedure to transform its supply chain architecture from a typical structure to a multi-agent structure. This procedure consists of seven phases. Initially, the case study is characterized as a supply chain, then the information is collected, next the limitations of the supply chain are identified, then the variables and their interactions are defined. In the following two phases, three models are developed: the structural model, representing the physical distribution of the plant; the conceptual model, that relates the system components and their interactions; and the functional model, which integrates the previous models and associates them with the behavior of the variables during the process flow. Finally, a qualitative and quantitative validation of the models are performed, simulating different scenarios. The results show that a distributed supply chain structure, using multi-agent architecture, first, offers robust information and physical flows, and secondly, contributes to supply time reduction, communication quickness, efficiency and quality of information for operational decision making. The results could also motivate organizations to integrate the supply chains considering MASs in resource management.
\end{abstract}

Keywords. Multi-agent Architecture, Supply Chain, Colored Petri Nets, Simulation.

Resumen. Este estudio propone una arquitectura basada en múltiples agentes a través de un modelo Red Petri Coloreada, que permite la integración de los eslabones de la cadena de suministro y la tecnología de la información para agilizar el proceso productivo y los servicios. La metodología se desarrolló en base a tres conceptos fundamentales: CPN como herramienta de diseño, Arquitectura de cadena de suministro y Sistemas Multi-Agente. Como caso de estudio se consideró el rediseño de una típica cadena de suministro en el sistema productivo colombiano. Para esto, el estudio desarrolló un procedimiento de modelado para transformar la arquitectura de la cadena de suministro del estudio de caso seleccionado a una estructura multi agente. Este procedimiento consta de siete fases. Inicialmente, el estudio de caso se caracteriza como una cadena de suministro, luego se recolecta la información, luego se identifican las limitaciones de

1 e-mail: oscar.rubiano@correounivalle.edu.co

2 e-mail: jose.i.garcia@correounivalle.edu.co 
la cadena de suministro, luego se definen las variables y sus interacciones. En las siguientes dos fases se desarrollan tres modelos: el modelo estructural, que representa la distribución física de la planta; el modelo conceptual, que relaciona los componentes del sistema y sus interacciones; y el modelo funcional, que integra los modelos anteriores y los asocia con el comportamiento de las variables durante el flujo del proceso. Finalmente, se realiza una validación cualitativa y cuantitativa de los modelos, simulando diferentes escenarios. Los resultados muestran que una estructura de cadena de suministro distribuida, que utiliza una arquitectura multi-agente, en primer lugar, ofrece información sólida y flujos físicos, y en segundo lugar, contribuye a la reducción del tiempo de suministro, rapidez de comunicación, eficiencia y calidad de la información para la toma de decisiones operativas. Los resultados también podrían motivar a las organizaciones a integrar las cadenas de suministro considerando los Sistemas Multi-Agente en la gestión de recursos.

Palabras Clave. Arquitectura multi-agente, cadena de suministro, redes de Petri coloreadas, simulación.

How to Cite. J. I. García-Melo and O. Rubiano-Ovalle, "Distributed architecture for a supply chain byintegrating a multi- agent approach using simulation", Jou. Cie. Ing., vol. 13, no. 2, pp. 1-23, 2021. doi $10.46571 / \mathrm{JCl} .2021 .2 .1$

Received: 24/05/2021 Revised: 23/06/2021 Accepted: 10/09/2021

\section{Graphic abstract}

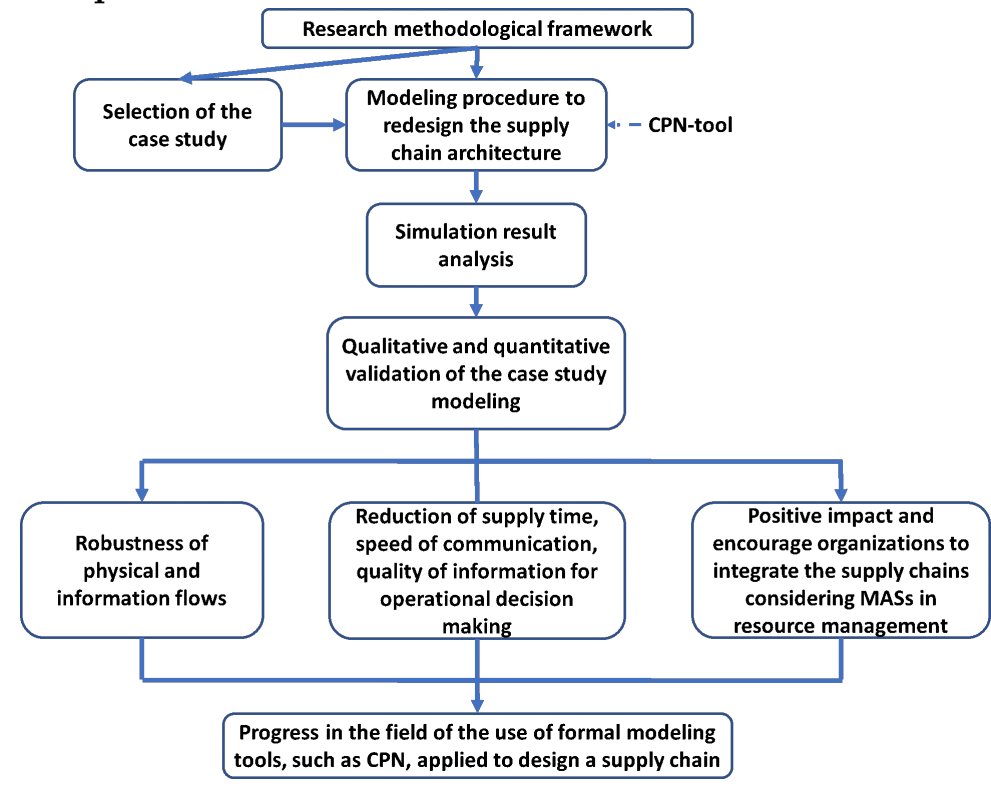

\section{Introduction}

Supply chain decision making has evolved over the years from a traditional architecture (with different aspects to improve, such as interdepartmental conflicts, weak leadership, slow flows, low quality data and low security, etc.) to a dynamic architecture that allows greater flexibility, integration and agile response times, promoting the optimization of resources [1, [2]. On the other hand, distributed systems, due to their articulating nature of decentralized computing agents, have been for several decades a paradigm that both has evolved and has contributed to the development of the integration of other information and communication technologies to the Supply Chain Management (SCM). This has allowed the incorporation of intelligent decision-making by service-oriented nodes, in an integration environment, and with a focus on creating value for customers. Some authors recommend studying architectures such as: architecture based on artificial intelligence [3], control architectures (distributed, centralized 
and mixed) [4], architecture with a holonic approach [5], business architecture [6] and industry 4.0 structure [7], [8].

According to Basole et al. 9], computer systems integrated into SCM based on intelligent agents, offer an adequate analytical approach, since they help to identify the technical and relational aspects of Supply Chain (SC), occurrence of possible events and permanent knowledge of consequences on performance [10], for example, they empirically showed that the supply network companies that integrate SC actors through a horizontal structure, tend to be in more dominant and influential positions than those that have a vertical structure, promoting both cost reduction and improvement of operational efficiency, and ultimately leading to better operational and business performance. In another study presented by Yuvaraj [11, the strength of supply network relationships is identified with the help of new technologies, such as: Internet of Things (IoT) and Low Power Wireless Communication Systems, which facilitates the exchange of knowledge.

On the other hand, an agent is "a computer system that is located in an environment, and is capable of taking autonomous actions in that environment in order to meet its design objectives" [12]. According to Wooldridge et al. [13], "An agent is an autonomous and flexible computer system, which is capable of acting in an environment". Likewise, the agent has the ability to perceive, process and perform autonomous actions to achieve the design objectives. Agent systems might have different architectures, such as: deliberative, reactive, hybrid and multi-agent [14].

The multi-agent architecture is a conglomerate of agents performing specific and collaborative functions among them [15]. Aguilar et al. [16], emphasizes the usefulness of multi-agent systems as a modeling tool in order to incorporate their main characteristics and benefits: autonomy, mobility, rationality, reactivity, sociability, and proactivity. This study specifically aims to propose a multi-agent based distributed architecture that leads to overcome these challenges. Considering the dynamics of the different flows between the nodes of the event- oriented supply chain, the Colored Petri Net was used for the verification and validation of the structure of the proposed supply chain. In this architecture the set of interactions between the nodes (agents) of the chain, act in a distributed manner, determining a set of operational and logistical decisions, and generating the information and physical processes among the Nodes. In this way, the advantages of information transmission and processing speed, flexibility, reaction and robustness of distributed systems are also exploited by [17] to create the proposed architecture. It is a simulation model, using the Colored Petri Nets tools (CPN) [18], [19].

The application of CPN is justified by its analytical and graphical strengths, moreover, is appropriate for representation, process analysis, and also has the ease to show systems where the synchronization of communication and the shared use of resources are important [20. The Petri nets (PN) concept was introduced by Carl Petri in 1962 [21]. According to Lin [18, the PN is a graphical and mathematical modeling tool used to study systems that present concurrent, asynchronous, distributed, parallel, non-deterministic and/or stochastic behavior; their graphic part can be used as visual aid similar to a state diagram or flow chart. One of the main characteristics of CPN is that they have the ability to associate a set of values (called color) with each object (mark). The use of colors is analogous to the use of data types in the programming languages, which gives $\mathrm{CPN}$ the necessary power to formalize the model of any system, no matter how complex it is, due to the capabilities of CPN with the capabilities of a high-level programming language [22, [23, [24]. CPN Tools is originally developed by the CPN Group at Aarhus University from 2000 to 2010. From the autumn of 2010, CPN Tools was transferred to the AIS group, Eindhoven University of Technology, The Netherlands.

The paper is organized in seven sections, including the introduction. The second section presents the literature review carried out to extract contributions that were starting point for this development. In the third section the methodology adopted for the present research is 
discussed. The fourth section presents the description of the case study. The fifth section elaborates the application of the methodology adopted to develop the modeling of the case study. The sixth section deals with the results of the modeling procedure and simulations, as well as, comparison of the current architecture against the proposed one. Finally, section seven is devoted to present the conclusions.

\section{Literature review}

Multi-agent systems (MAS) have been recognized as ideal for modeling and analyzing the structure and dynamics of complex industrial systems, such as supply chains. For this reason, they are especially useful for evaluating different flow architectures of these production and distribution systems. Hmida et al. [25] presented a MAS evaluation method highlighting the communication and transfer of information between links of a SC modeled by agents, as this is one of the most important functional features of distributed systems in general and MAS in particular. Shoham [26, established Agent-Oriented Programming (AOP) approach, where by multi-agent systems become a specialization of distributed Object-Oriented systems. The approach of agents as service centers is presented by Pal Karakostas [27], who introduced a multiagent and web services framework for the Collaborative Materials Procurement System (CMPS) in a supply chain. Jaimez-González \& Luna-Ramírez [28] presented a multi-agent architecture by modeling a supply chain, which explored different strategies and offered solutions in a distributed e-commerce environment. The authors showed how the entire multi-agent system developed and implemented a collaborative agent. Zhao [29], developed an agile SCM architecture based on the exchange of information from multiple agents under the guidelines of the theory of selforganization. In turn, they proposed a prototype of the SCM system using web technology, distributed object technology (CORBA/DCOM) and management technology and organization of related information resources. Perera Karunananda [30], developed a model in which each phase of the supply chain was developed as an agent that allowed communication, coordination and negotiation between agents to achieve the intended business objectives.

Table 1 presents an overview of the recent contributions that relate SC and MAS modeling through literature review.

According to the analysis of the Literature, the authors of this research conclude that it is necessary to strengthen the research on the integration between MAS and CS, incorporating formal modeling approaches, thereby contributing to the evolution of SCM in the era of industry 4.0. Specifically, the literature on MAS as an approach to modeling supply chains using Colored Petri Nets is sparse. Among the few authors who addressed this gap, we found that Quan et al. [40] propose the development of a multi-agent system based on the characteristic of a cooperation protocol, which uses distributed artificial intelligence studies, offering interaction models to consult tasks among multiple agents, through CNP tool. Aggarwal [41], developed a work using CPN from a multi-agent approach for the development of a system for assigning tasks dynamically, this study evaluated the creation of a model where the assignment of tasks between a given number of agents is dynamic and not deterministic. Similar works to simulate multi-agent systems using CPN can be developed by [42, ,43] to a dynamic task allocation and the asynchronous relation among them, respectively. These antecedents encourage the contribution of this research based on the objective: to offer progress in the use of formal modeling tools, as in this case, Color Petri Nets, applied to design a supply chain, conceived as a distributed system based on MAS.

\section{Methodology}

The global methodology formulated is represented in figure 1, which integrates the three used concepts. This methodological framework was developed in the following major steps: i) Preliminary literature review about the three fields or concepts: SC architecture, supply chain 


\begin{tabular}{|c|c|c|}
\hline References & $\begin{array}{c}\text { Papers } \\
\text { analyzed }\end{array}$ & Authors'observations \\
\hline [31] & 42 & $\begin{array}{l}\text { Authors highlight the impact of the integration between MAS and the supply chain in the } \\
\text { economic, environmental and medical areas. The authors recommend application studies } \\
\text { of this integration to carry out medium and long-term planning. }\end{array}$ \\
\hline [32] & 41 & $\begin{array}{l}\text { The job Identify seven challenges: } i \text { ) Regulation, } i i \text { ) standardization of communication } \\
\text { and negotiation Protocols, } i i i) \text { Flexible design, iv) Responsiveness, } v \text { ) gain sharing, vi) } \\
\text { Autonomy, vii business and governance model. The authors value these seven challenges } \\
\text { for practical purposes for organizations in the fields studied. }\end{array}$ \\
\hline [33] & 105 & $\begin{array}{l}\text { The authors highlight the increase in the coordination and response capacities of a supply } \\
\text { chain from the integration of MAS-based modeling. Additionally, they qualify the } \\
\text { negotiation policies in international environments, as a field of special interest. }\end{array}$ \\
\hline [34] & 264 & $\begin{array}{l}\text { Research defines that MAS-supply chain integration offers a resource optimization } \\
\text { environment. The authors suggest improving design methodologies to overcome different } \\
\text { challenges, such as: technological and commercial. Research also visualizes an extension } \\
\text { of this integration with other technologies, such as: Big data, IoT and Blockchain. }\end{array}$ \\
\hline [35] & 59 & $\begin{array}{l}\text { The authors present exponential growth in MAS-Supply Chain integration applications. } \\
\text { The authors recommend improvements in design methodologies integrating modeling } \\
\text { tools. Additionally, they suggest a standardization to favor applications among } \\
\text { international organizations. }\end{array}$ \\
\hline$[36]$ & 127 & $\begin{array}{l}\text { The authors identify the strengths of a collaborative supply chain in different areas. } \\
\text { However, they identify a limited literature in works related to the evaluation and impact } \\
\text { of environmental and social performance. }\end{array}$ \\
\hline [37] & 21 & $\begin{array}{l}\text { The authors identify the strengths of integrating knowledge management tools into the } \\
\text { structure of a supply chain. On the other hand, question the limited literature related to } \\
\text { integrated knowledge management in the design of supply chains and MAS. }\end{array}$ \\
\hline [38] & 79 & $\begin{array}{l}\text { This work evidences an area of research in the standardization of the relationship between } \\
\text { MAS and supply chains through the modeling of Industry } 4.0 \text {. } \\
\text { The authors recommend further research on methodologies, design tools and professional } \\
\text { training plans in the area. }\end{array}$ \\
\hline [39] & 9 & $\begin{array}{l}\text { The authors identify the optimization of resources as one of the main advantages of } \\
\text { integrating MAS into a production system. Additionally, the work identifies an } \\
\text { application opportunity in the area of performance evaluation and diagnosis. }\end{array}$ \\
\hline
\end{tabular}

Table 1: Summary of recent Authors' observations on SC and MAS modeling

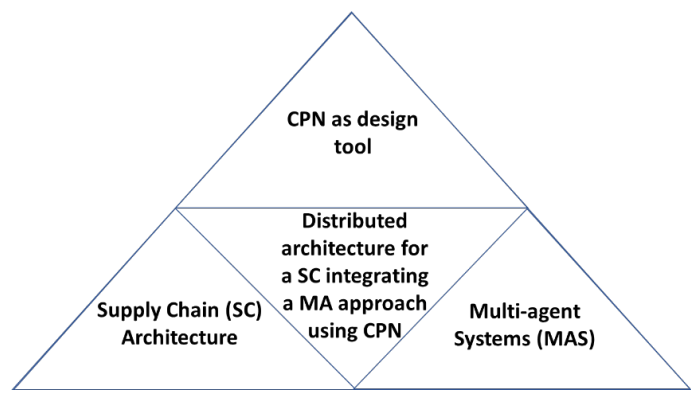

Figure 1: Research methodological framework

modeling using CPN, and supply chain modeling using MAS, ii) Definition of the problem in terms of the gap present in the modeling that combines the three concepts, iii) Selection of the case study, iv) Definitive literature review, v) Meetings with case study organization managers to carry out the information collection plan and develop the modeling procedure for redesign the supply chain architecture, which includes simulation and analysis of results, vi) Modeling 
procedure to redesign the supply chain architecture, v) Simulation result analysis.

The modeling procedure for redesigning the supply chain architecture (Figure 2), allowed to work with the relevant information on the typical structure, to migrate to the architecture that incorporates the MAS approach.

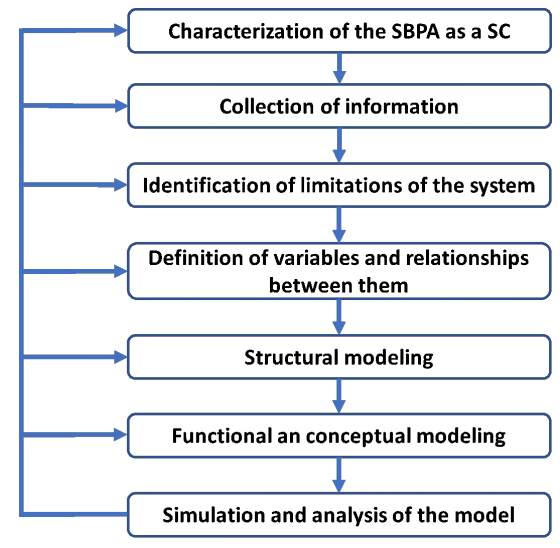

Figure 2: Modeling procedure to redesign the supply chain architecture

\section{Case Study}

For the application of the methodology developed in this research, a Simulation Bank (Laboratory) for the Product Assembly (SBPA), located in a training-for-employment institution called the National Learning Service (in Spanish, Servicio Nacional de Aprendizaje, acronym: SENA) in Cali, Colombia was adopted as a case study. SBPA's objective is to make and transfer a final product, assembling four components sequentially: cylinder, piston, spring, and lid. The lid and cylinders have three different color options, each color combination between the cylinder and the lid represents a different product reference. The initial system typified as a traditional supply chain, is made up of five modules: distribution, robot, join, storage, and classification, that interact in an automatic environment of transactions and information and raw materials flows; each module corresponds to a link or node of the SC (Figure 3). The distribution module is integrated for several pneumatic devices in order to supply the components of the final product.

The robot module allows the automatic assembly of the different parts that constitute a final product. The assembled product is transported to the join module. The join module consists of the supply warehouses for the lids and springs components. In the event that the inventory of components reaches their reorder point in a warehouse, a replenishment signal is sent for their supply. The storage module has two functions: i) Storing the products according to their color, ii) Delivering the products in process to the sorting station. For this, this module is made up of a three-level warehouse, with six places on each level, and a robotic system. The classification module allows to organize the assembled products according to the color of the cylinder. For this, the module is integrated by a color-checking sensor, a conveyor belt and a sorting unit.

This case was chosen given the easy access to information and the flexibility of these modules to configure different SC architectures, which allows evaluating the design proposal of a distributed architecture for a supply chain integrating multi-agent technology.

\section{Case Study Modeling}

5.1. Characterization of the SBPA as a $S C$

Initially, the modules of the SBPA system were linked in the context of a traditional or typical CS architecture, shown in the figure 4. In this structure, the supplier and external customer 


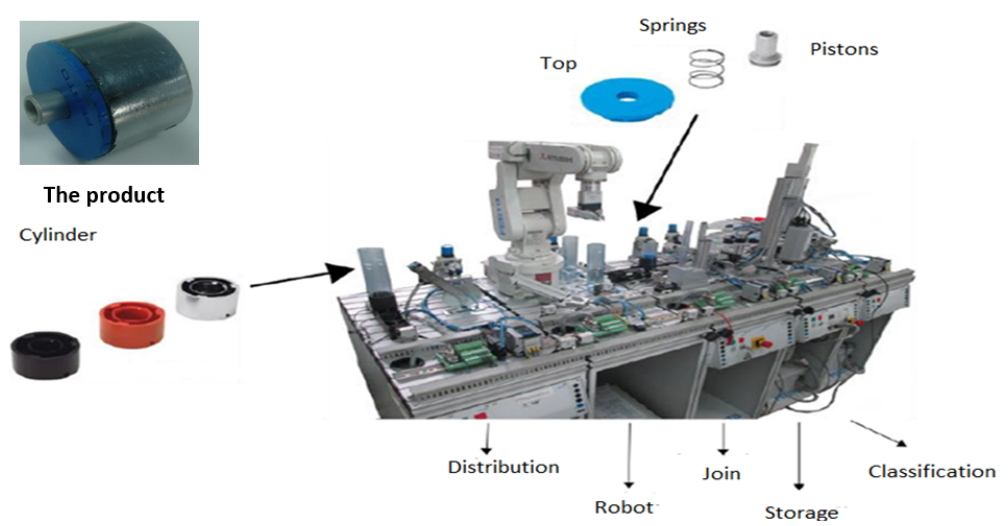

Figure 3: Simulation Bank for Product Assembly - SBPA

are included as external links; the link "manufacture" is in charge of executing activities of production into the CS, is integrated by the robot and assembly modules. The transport link, responsible for the delivery activities of the production into the CS, is represented by the distribution and storage modules, and the retailer link is integrated by the classification module. This is a typical eminently sequential structure, in which the links, instead of working

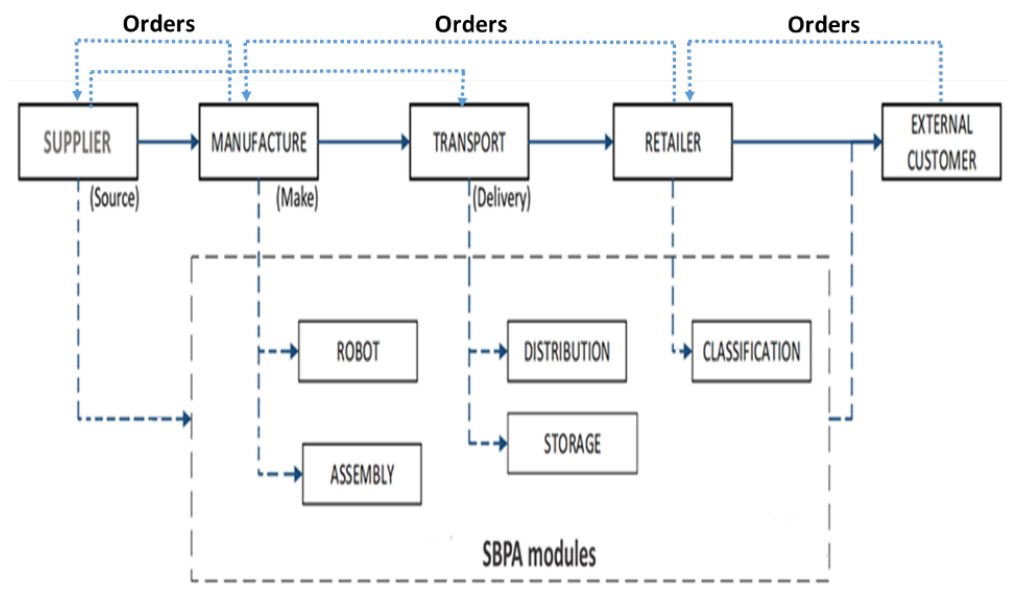

Figure 4: SBPA's vision as a typical supply chain

in an integration environment, these do it by pursuing individual objectives, forgetting the end customer and generating complexities related to information and physics flows, in terms of well-known bullwhip effect [44.

Figure 5 shows the characterization of the operation of the manufacturer link, using a SIPOC (Suppliers - Input - Process - Output - Customer) diagram.

\subsection{Collection of Information}

In this initial stage, field visits are carried out in order to collect information in order to characterize the system. The following are the types of information collected: parameters, functions, and operating standards, among others. A conceptual map of this phase is presented in figure 6. 


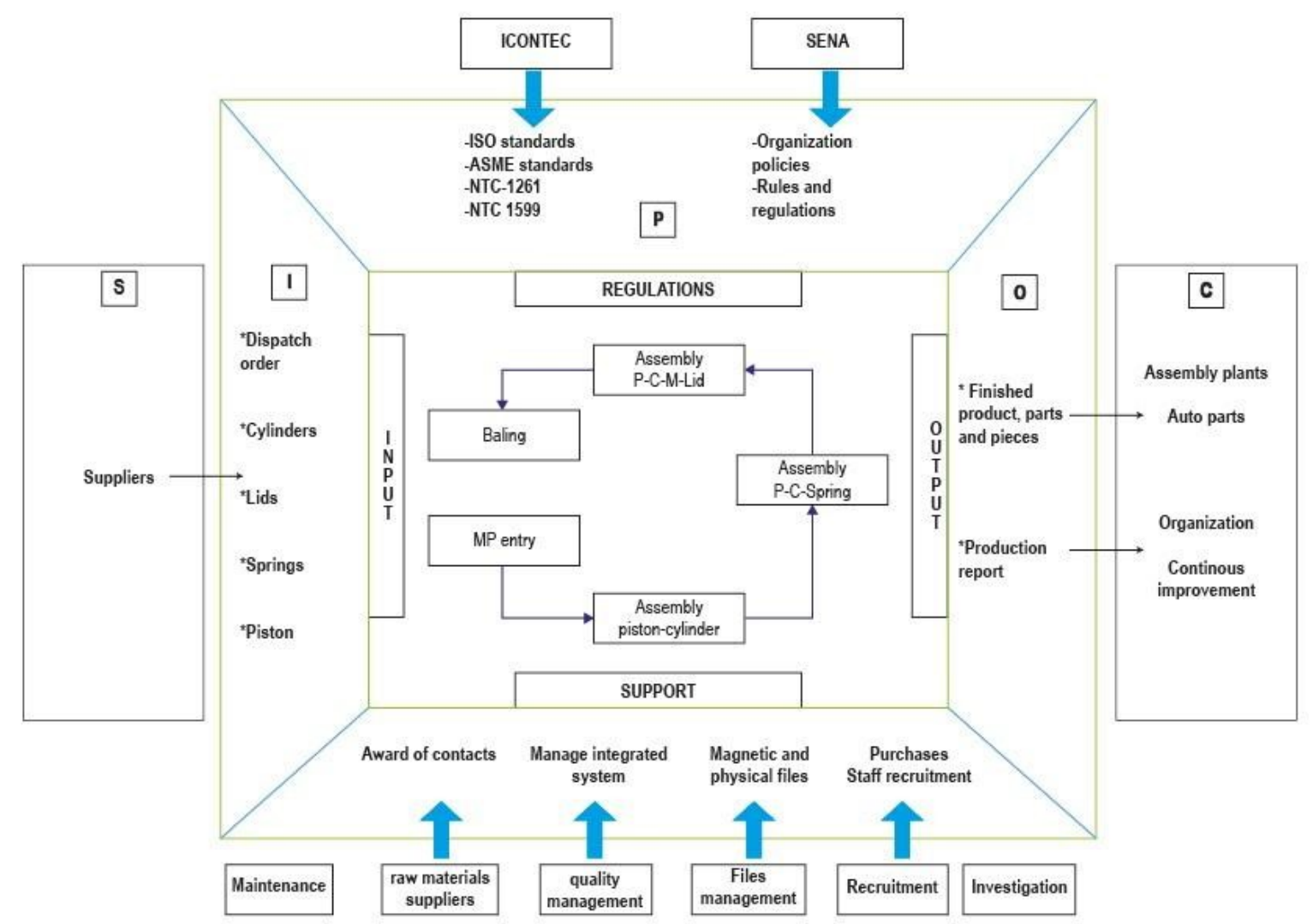

Figure 5: SIPOC of the manufacturer link

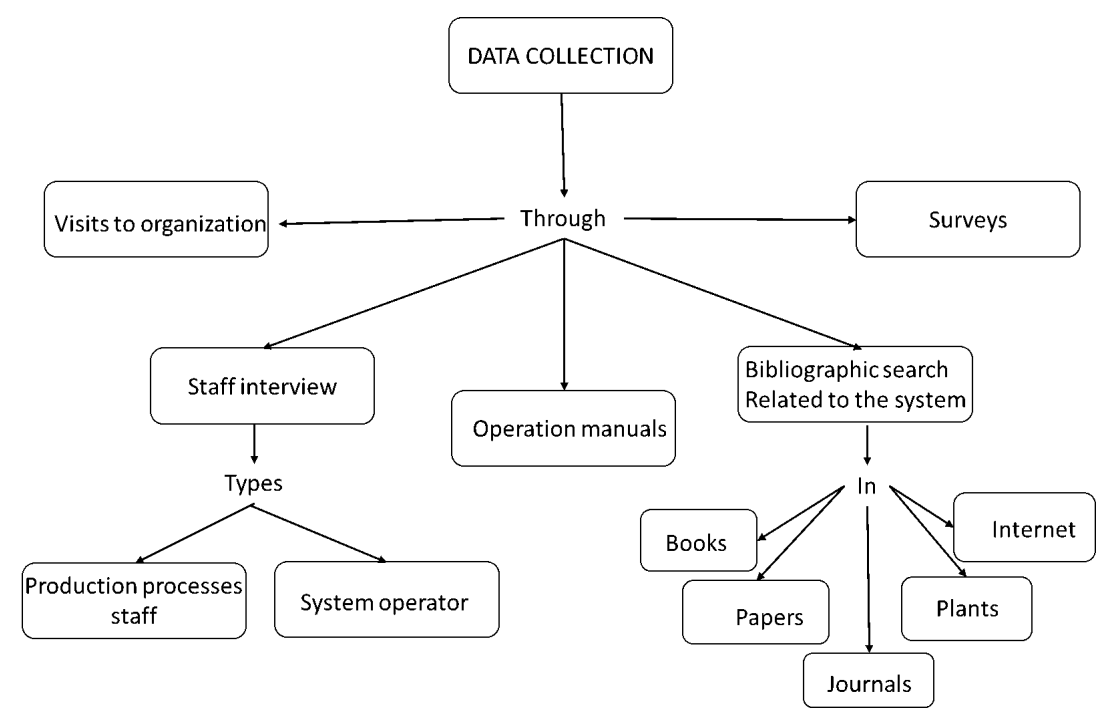

Figure 6: A conceptual map of the Collection of information phase

\subsection{Identification of Limitations of the System}

These limitations are related in several aspects, for example, organization's policies, commercial and the manufacturing strategies, among others. 


\subsection{Definition of Variables and Relationships Between Them}

On this step the following concerns are addressed: required production activities, type of resources required, type of information and products required, type of relationship among devices necessary, type of relationship among the involved variables necessary.

\subsection{Structural Modeling}

Based on results from previous stages, the modules that compose the system are identified (machines, devices, etc.). To develop the model from an intelligent agent approach, the intelligent actions that were intended to model under the multi-agent orientation were determined.

\subsection{Functional and Conceptual Modeling}

On this step the relationship of the system components is conceptually described (interaction among links), also the functions that define the variables behavior during the process flow are established. At this stage the CPN-Tools software is used, in addition for defining the characteristics of the marks that represent the flow of resources or information through the model network.

\subsection{Simulation and Analysis of the Model}

In this stage, the following parameters and indicators, showed in the problem map, are those defined for formulating simulation scenarios. The problem map (figure 7) is a structure that specifies in an image, the function $\mathrm{F}$ (parameter values, $\mathrm{Xs}$ ) = Results of model performance indicators, Ys, where function $\mathrm{F}$ is the multi-agent $\mathrm{SC}$ model.

\section{Scenario definition parameters $(X s)$ :}

- Production rate (PR): It is the number of normalized units per time unit in which can be performed a task for a combination from an $\mathrm{x}$-axis value (time) and a $\mathrm{y}$-axis value (quantity) from the Table of normalized times, multiplied by a conversion factor. This results in the amount that the organization intends to manufacture or provide to the market to meet the demand.

- Mobilization of products from manufacturer to retailer (MPMR): it is the number of on-time transported products from the manufacturer warehouse link to the retailer warehouse link.

- Communication level in the process (CLP): It's the amount of information transmitted bi-directionally correctly to each one of the links participating in the process. Can be measured as the number of messages sent and received by a given link correctly.

Indicators of system performance ( $Y$ s):

- Service Level (SL) indicator: It represents the expected probability of not falling into a stock out situation.

- Permanency time of the product in the SC (PTPSC): It's the time that a product stays since their raw material (RM) source until it is transformed to a final product and delivered to the retailer link.

- Connection time in communication between links (CTCL) indicator: It is the time required to transmit a successful message from one link to another inside the SC.

- Average inventory (AI) indicator: It is the average among the existent values on the inventory and the new purchase values.

The problem map of the SBPA SC model conceived as a mathematical function $\mathrm{F}(\mathrm{X})=\mathrm{Y}$, allows to define the scenarios, simulate them and obtain performance results of the model. 


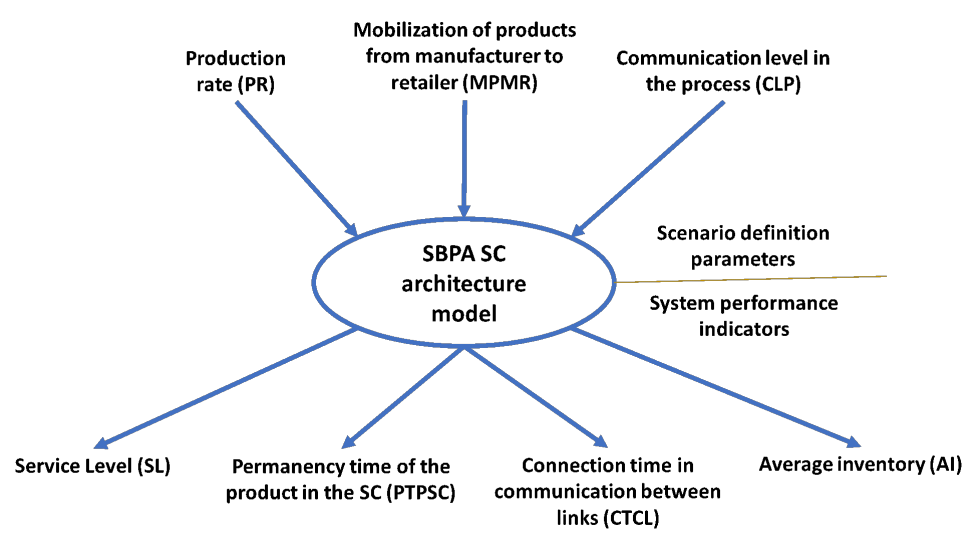

Figure 7: Multi-agent SC model problem map

\section{Results and discussion}

In this section we present the results of applying the Modeling procedure to redesign the supply chain architecture for both typical and distributed SC.

\subsection{Modeling the Architecture of the Typical SC Using CPN}

In the typical model of the SBPA SC (presented above on figure 2), the manufacturer link, operates essentially under a push approach, is oriented to use the available infrastructure capacity, without taking into account the market (retailer) demand requirements, so the SC is oriented to assemble and distribute products in large batches regardless of whether the customer requests them or not, resulting on an inventory increase and obsolescence. Likewise, the retailer makes requirements to the manufacturer regardless of the demand of the external customer.

The manufacturer link starts with a production order (PO) released, verify the existence of raw materials (RM) and if necessary, it requests it from the supplier link based on needs forecasts. Manufacturer value stream consist of six workstations (1) RM reception, (2) cylinder and piston assembly, (3) spring assembly, (4) lid assembly, (5) finished product packaging and (6) product dispatch. The finished products are distributed by the transport link, it takes them from manufacturer module and takes them to the retailer link. The "Retailer" link receives the products sent from the "Manufacturer", on a warehouse, and locate the stock on hold until the external customer consumes them. Table 2 shows the variables and limitations considered for each of the links in the typical SC model. The production and distribution process are similar for every reference in the case study, thus, a representative model for the process flow is defined (figure 8). Once the model represented the current SBPA SC, it was simulated to validate its behavior. The simulation results and parameter values of the current situation are presented on Table 3.

\subsection{Modeling the Distributed Architecture of the SBPA SC}

In figure 9 is shown the proposed SBPA SC multi-agent architecture, consisting of six links. The "Customer"- external customer is the first link; this has a direct bidirectional relationship with "Retailer"- retailer link. The architecture counts with two agents, the "logistics operator agent"logistic provider agent and "Integrative agent"- integrative agent, which is inter-related to every other link except to the external customer. The "Provider" supplier link is communicated with "Integrative agent" and also with "Manufacturer" link. Additional information is considered in relation to the new links represented by the logistic and integrative operator agents, which are described below: 


\begin{tabular}{|c|c|c|}
\hline SC links & Activities and variables & Restrictions \\
\hline $\begin{array}{l}\text { External } \\
\text { Customer }\end{array}$ & $\begin{array}{l}\text { - Delivery time } \\
\text { - Product quantity } \\
\text { - Type of product }\end{array}$ & $\begin{array}{l}\text { - The customer can purchase the product that is on the shelf, } \\
\text { in addition, the order can be completed with an existing } \\
\text { product in the retailer's warehouse. }\end{array}$ \\
\hline Retailer & $\begin{array}{l}\text { Receives orders from the } \\
\text { external customer and send } \\
\text { orders to the manufacturer } \\
\text { - Quantity and type of } \\
\text { product }\end{array}$ & $\begin{array}{l}\text {-The retailer does not make a product request without first } \\
\text { consulting their inventories, both on the shelf and in their } \\
\text { warehouse. } \\
\text { - The retailer cannot place an order that exceeds its storage } \\
\text { capacity (product on shelf and product in warehouse). } \\
\text { - A purchase order is generated towards the shelf, when the } \\
\text { product stock on the shelf is below } 10 \text { units. } \\
\text {-The retailer's warehouse generates an order for the product } \\
\text { when its stock is also below } 10 \text { units. }\end{array}$ \\
\hline Transport & $\begin{array}{l}\text { Receives orders from the } \\
\text { manufacturer and provide the } \\
\text { goods mobilization service }\end{array}$ & $\begin{array}{l}\text { - The merchandise is only moved by the trucks designated } \\
\qquad \text { by the company. } \\
\text { - Unlimited truck capacity. } \\
\text { - The following parameters are not considered for this } \\
\text { moding: } \\
\text { Fortuitous events (strikes, delays, natural disasters, crashes) } \\
\text { - Scheduled events such as: maintenance, calibrations, etc. }\end{array}$ \\
\hline Manufacturer & $\begin{array}{l}\text { Receives confirmation to } \\
\text { execute production orders, } \\
\text { generate RM acquisition } \\
\text { orders, approve execution of } \\
\text { production orders when } \\
\text { resources are available } \\
\text { - Product quantity } \\
\text { - Kind of product }\end{array}$ & $\begin{array}{l}\text { The following parameters are not considered for this } \\
\text { modeling: } \\
\text { - Preparation of machinery. } \\
\text { - Fortuitous events: stoppages, delays, natural disasters } \\
\text { - Scheduled events such as: maintenance, calibrations }\end{array}$ \\
\hline Supplier & $\begin{array}{l}\text { Receives orders, processes } \\
\text { them and dispatch them } \\
\text { - Generates confirmation of } \\
\text { delivered RM }\end{array}$ & $\begin{array}{l}\text { Delays in RM delivery are not considered } \\
\text { - The provider has unlimited products from the previously } \\
\text { selected resources } \\
\text { - For each item, only one supplier is considered. }\end{array}$ \\
\hline
\end{tabular}

Table 2: Variables and limitations of the typical SC

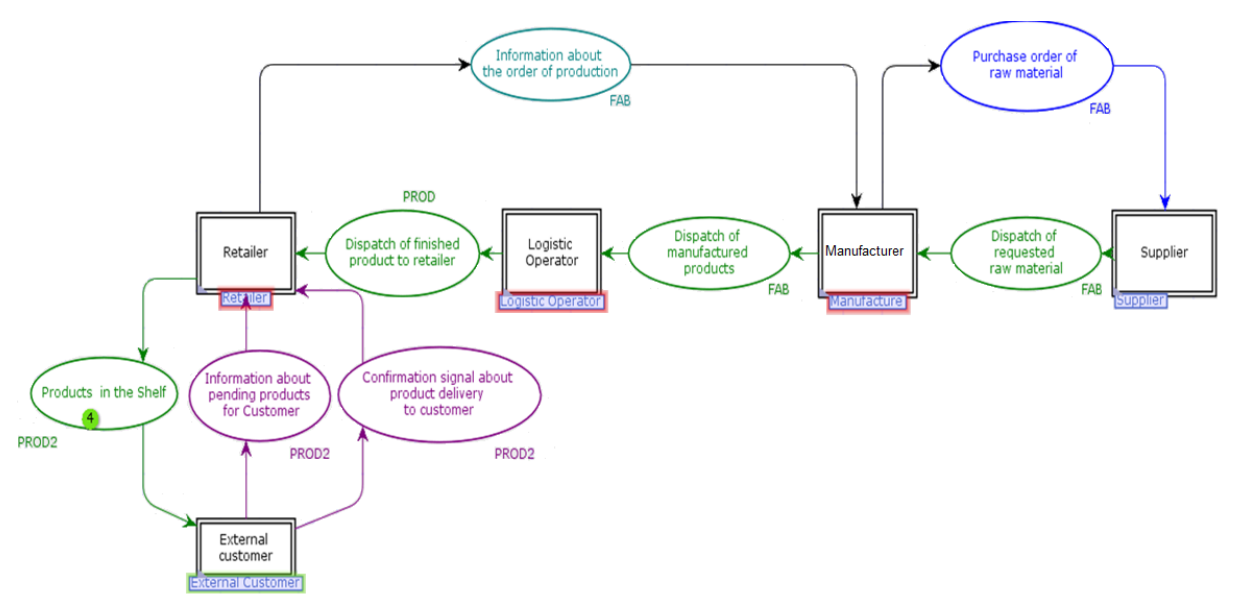

Figure 8: Model of the typical architecture of the SBPA SC 


\begin{tabular}{ccc}
\hline SC links & $\begin{array}{c}\text { SC Time } \\
\text { (seconds) }\end{array}$ & $\begin{array}{c}\text { SC Time -CPN } \\
\text { (seconds) }\end{array}$ \\
\hline Suppliers & 3.5 & 3 \\
\hline Manufacturer & 11 & 10 \\
\hline Transport & 2 & 2 \\
\hline Retailer & until sales & until sales \\
\hline $\begin{array}{c}\text { External } \\
\text { customer }\end{array}$ & Random & Random \\
\hline
\end{tabular}

Table 3: Simulation results of the current architecture of the SBPA SC

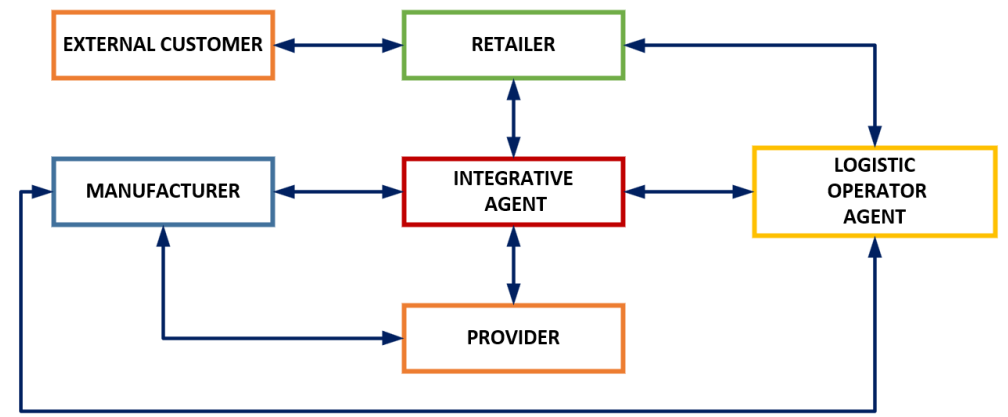

Figure 9: Proposed architecture of the SBPA SC

Logistic operator agent ( $L O A)$ : This link is in charge of the distribution, internal inventory management in the manufacturer warehouse, selection and dispatch of vehicles to retailer and the associated information to this process. The functions of a logistics operator are as follows: order processing, material handling, packaging, transportation of products, storage, inventory control, customer service:

Integrative agent (IA): Being a SC information manager, interacts with every link except external customer. The integrating agent considers the following policies:

- General policies: They must be known to all and serve as a guide.

- Departmental policies: They are the principles to be followed by each department or service. The most common are, the quality policy, the environmental policy and the production policy for a specific product.

\subsection{Identifying Limitations of System}

The activities, variables and limitations identified are shown on Table 4.

\subsection{Conceptual and Functional Modeling}

6.4.1. Conceptual Model In this stage all the functional relationships of each CS process are defined, it is described as the flow of the variables and the operations carried out at each stage and component of the system, according to the architecture and policies proposed for the CS and the characteristics of the system.

figure 10 (a) corresponds to the flow chart of the external customer and the retailer processes, each box corresponds to an activity in the process and the number inside indicates the sequence in which each of the operations is carried out. Figure 10 (b) shows the flow diagram of the Logistics Operator and the integration of this link with each of the other links of the SC. Figure 


\begin{tabular}{|c|c|c|}
\hline SC Links & Activities and Variables & Limitations \\
\hline LOA & $\begin{array}{l}\text { - Number of available vehicles to perform } \\
\text { product dispatch } \\
\text { - Load capacity of the vehicle. }\end{array}$ & $\begin{array}{c}\text { - The LOA does not transport any commodities } \\
\text { without the integrative agent authorization } \\
\text { - Limited capacity of the trucks } \\
\text { - For this model are not considered the following } \\
\text { parameters: } \\
\text { * Incidental events (strikes, natural disasters, } \\
\text { collisions, etc.) } \\
\text { *Scheduled events as: maintenance } \\
\text { * Load and unload time frames are considered as } \\
\text { standard times }\end{array}$ \\
\hline IA & $\begin{array}{l}\text { - Inventory control of the central warehouse } \\
\text { within Manufacturer } \\
\text { - Production order assignment and approval } \\
\text { - Product delivery confirmation } \\
\text { - Processes the information generated by the } \\
\text { other links of the CS, such as: } \\
\text { * RM in warehouse } \\
\text { * Products in warehouse } \\
\text { - Articulates and coordinates the links }\end{array}$ & $\begin{array}{l}\text { Through this agent there is no physical flow of } \\
\text { goods } \\
\text { - Requires updated information of every process } \\
\text { - The processed information is distributed to each } \\
\text { of the AI's output ports and is received at the input } \\
\text { ports that are connected to the CS links }\end{array}$ \\
\hline
\end{tabular}

Table 4: Variables definition and limitation

11 (a) shows the flow chart of the Manufacturing and Supplier link. Figure 11 (b) presents the flow diagram of the Integrative Agent process, it interacts with four links of the CS except for the external Customer.

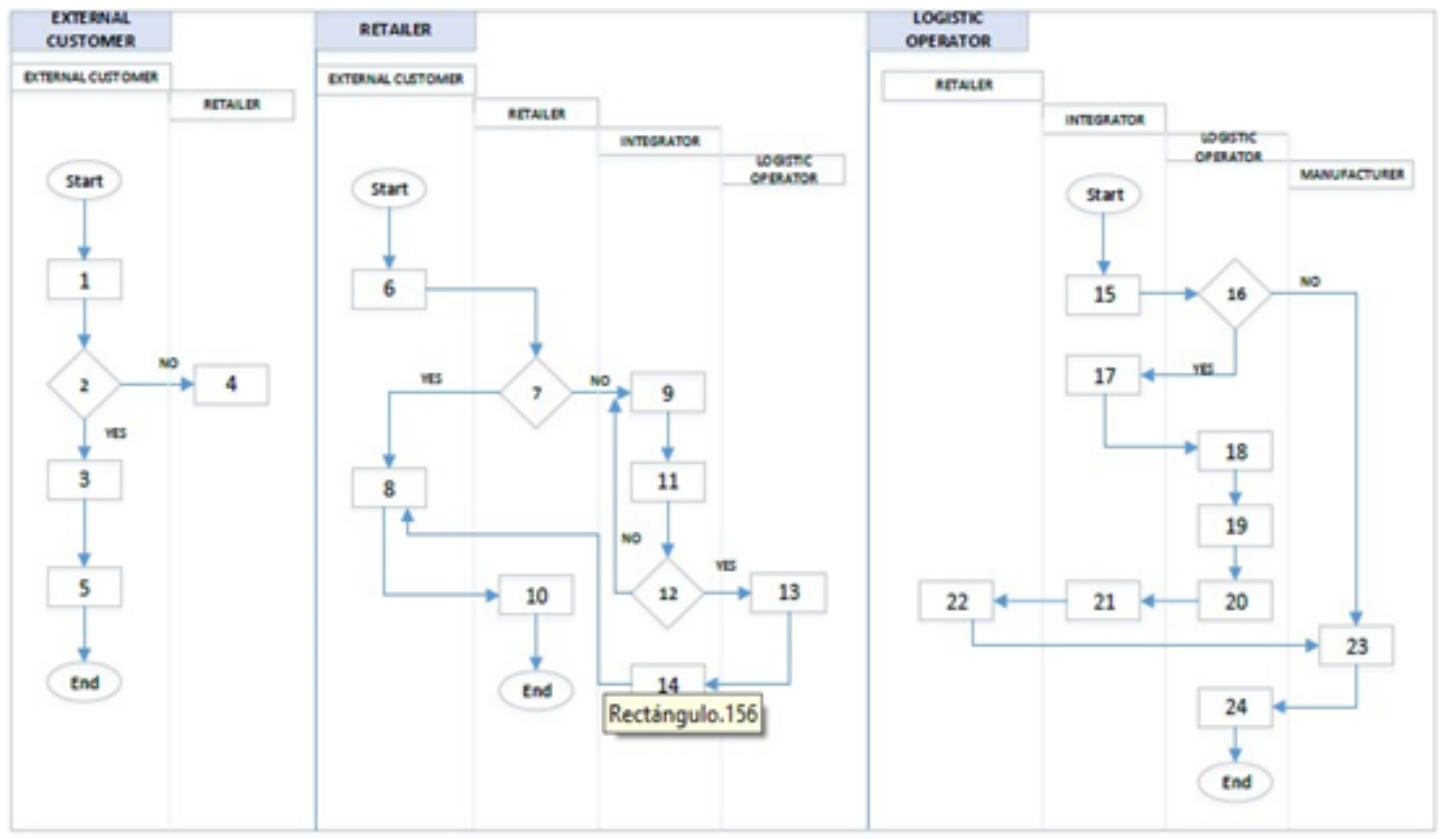

Figure 10: Conceptual diagrams of the process flows of (a) external customer and retailer, (b) logistics operator

6.4.2. Functional model In Figure 12 the global functional proposed SBPA SC model in CPN is shown. It's noted a numeration from 1 to 6 on the net transitions, indicating the SC links; the 


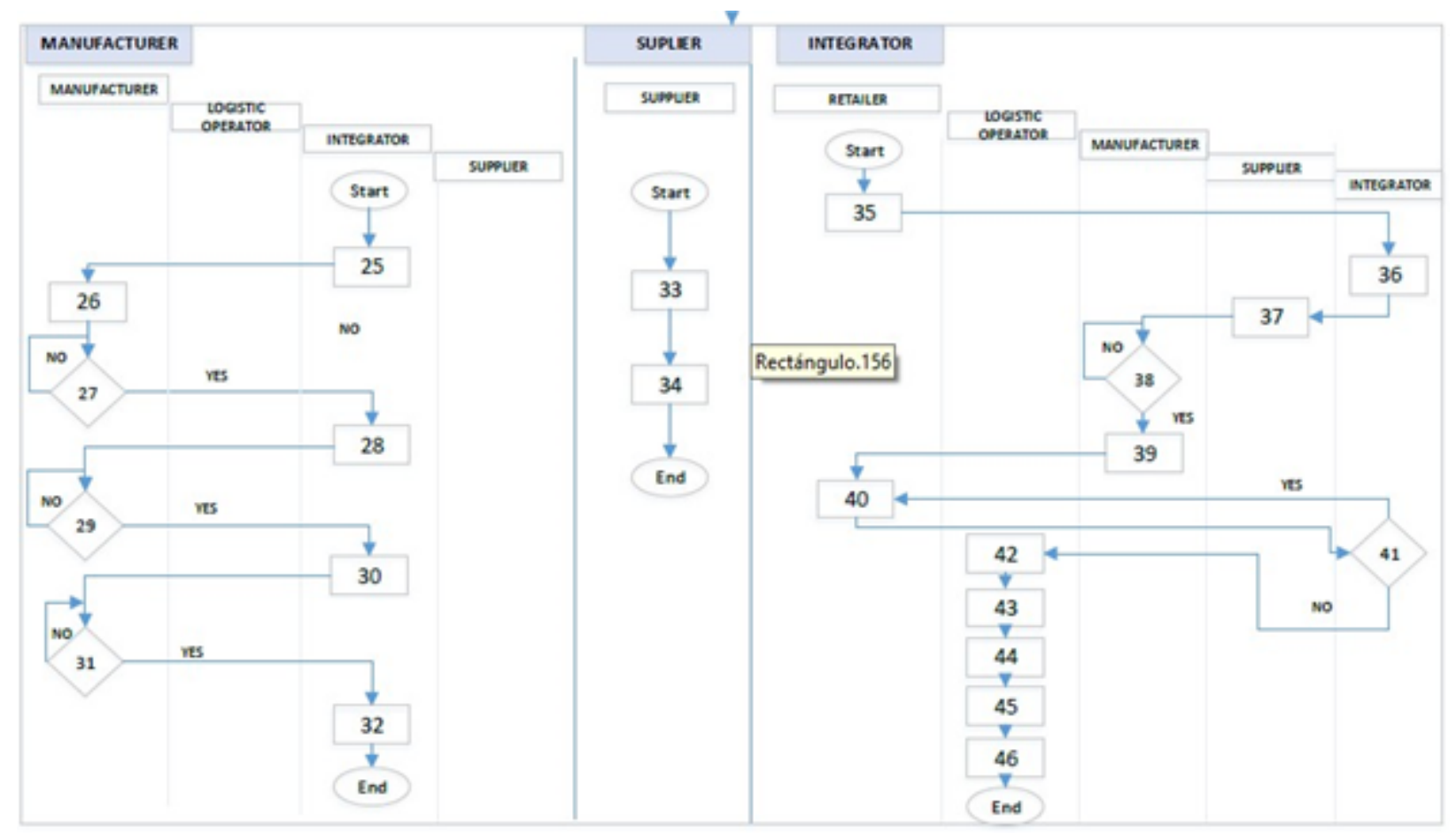

Figure 11: Conceptual diagrams of the process flows. (a) Manufacturer and supplier, (b) Integrative agent

places of the net represent the information flow (Blue, red, cyan, purple places) and SC products; while the product and raw material flow are represented by a green place (nomenclature $\mathrm{P}$ ), the direction of the flow of information and products in the CS is represented by the arcs of the network. Figure 13 shows the "Logistics Agent Operator", this link intervenes in the CS process

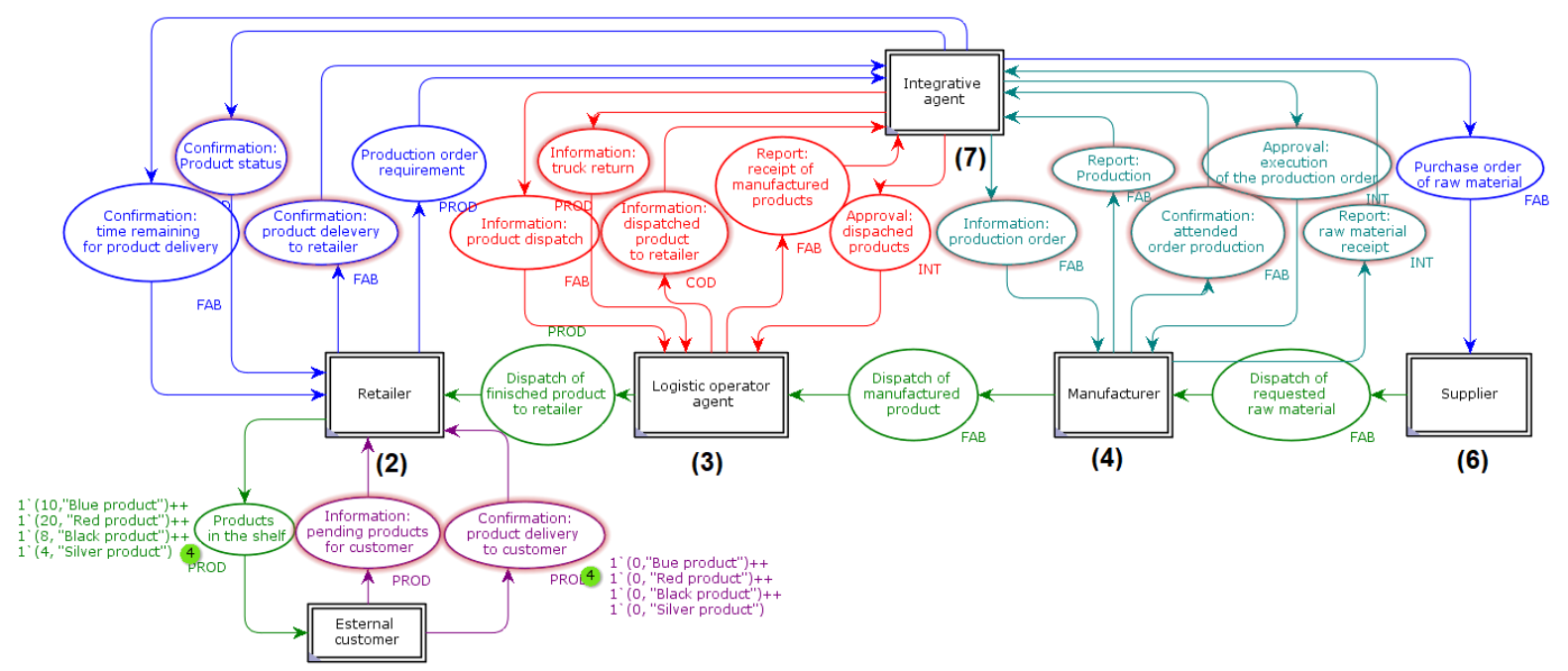

(1)

Figure 12: Model of the proposed architecture of the global SBPA SC 


\begin{tabular}{|c|c|c|c|}
\hline No. & Activity & No. & Activity \\
\hline 1 & Customer request & 24 & Trucks available for a new delivery \\
\hline 2 & Checks product in stock & 25 & $\begin{array}{l}\text { Receives information of production order } \\
\text { from integrative agent }\end{array}$ \\
\hline 3 & Sell and updates the inventory & 26 & Verifies the availability of work stations \\
\hline 4 & Identify of missing product & 27 & Checks the raw material from the Supplier \\
\hline 5 & Confirmation of product delivery to the customer & 28 & Receives raw material from Supplier \\
\hline 6 & $\begin{array}{c}\text { Receives information about missing product from extemal } \\
\text { customer }\end{array}$ & 29 & Checks production order status \\
\hline 7 & Checks Product in warehouse & 30 & Sends a confirmation to begin production \\
\hline 8 & Ships product from warehouse & 31 & Checks finished production \\
\hline 9 & Send production order request to integrative agent & 32 & Sends production confirmation status \\
\hline 10 & Send confirmation of product delivery to the customer & 33 & $\begin{array}{l}\text { Receives acquisition order for raw material } \\
\text { from integrative agent }\end{array}$ \\
\hline 11 & $\begin{array}{l}\text { Receives from integrative agent the confirmation about time } \\
\text { remaining for delivery and product status }\end{array}$ & 34 & Dispatch of production order required \\
\hline 12 & Checks the status of the product & 35 & $\begin{array}{l}\text { Receives from retailer the information of } \\
\text { request of production order }\end{array}$ \\
\hline 13 & Receives product from logistic operator & 36 & $\begin{array}{l}\text { Prioritizes the production order according to } \\
\text { the established criteria }\end{array}$ \\
\hline 14 & $\begin{array}{c}\text { Send information about product in warehouse to integrative } \\
\text { agent }\end{array}$ & 37 & $\begin{array}{c}\text { Creates production order and acquisition order } \\
\text { for raw material }\end{array}$ \\
\hline 15 & Receives production order from integrative agent & 38 & Checks order production report \\
\hline 16 & $\begin{array}{l}\text { Checks stock according to the order requested in central } \\
\text { warehouse }\end{array}$ & 39 & Sends approbation to begin production \\
\hline 17 & Waiting for dispatch approbation & 40 & $\begin{array}{c}\text { Sends to retailer information about delivery } \\
\text { time and product status }\end{array}$ \\
\hline 18 & $\begin{array}{l}\text { Product classification in units according to the truck } \\
\text { capacity }\end{array}$ & 41 & Checks delivery time \\
\hline 19 & Verifies availability of vehicles according to truck capacity & 42 & Sends signal to dispatch the products \\
\hline 20 & Selects, loads and dispatches truck. & 43 & $\begin{array}{l}\text { Receive from logistic operator the signal of } \\
\text { confirmation of product delivery }\end{array}$ \\
\hline 21 & Information about products dispatched to retailer & 44 & Sends the logistic operator information \\
\hline 22 & Checks delivered product & 45 & $\begin{array}{c}\text { Receives the information given by the logistic } \\
\text { operator }\end{array}$ \\
\hline 23 & Receives products from central warehouse & 46 & Receives the information given by the retailer \\
\hline
\end{tabular}

Table 5: Conceptual diagram activities

from the moment it receives the finished product from manufacturer, "Product reception from manufacturer activity". This agent is waiting for the confirmation signal from the "Integrative Agent" (information) and "Manufacturer" (product and signal) to mobilize the product from the central warehouses that it manages to the "Retailer". This information is represented by marking the states "Information: shipping order", "Information: truck return", "Shipping Approval" and "Final product in central warehouse", with the batch number, quantity, type of product and delivery time.

Internally, this agent has a subnetwork $(J)$ that is fed with the previous information for the selection of dispatch fleets (Figure 14). Truck selection starts when the "Supply to Retailer" transition is activated; Depending on the quantity of products to be dispatched, the agent is able to decide between three different types of trucks according to their loading capacities. Once the truck is selected, the product is dispatched (activating the transition "Dispatch Prod to the Retailer") and simultaneously a signal is sent informing the "Integrative Agent" of the 
dispatch of the products, by activating the status "Dispatch finished goods to retailer". It should be clarified that this same information is distributed by the "Integrative Agent" to the "Retailer". The "Logistics Operator" ends its intervention in the process, when the trucks return from the "Retailer. Figure 15 shows the network of the "Integrative Agent". Being a

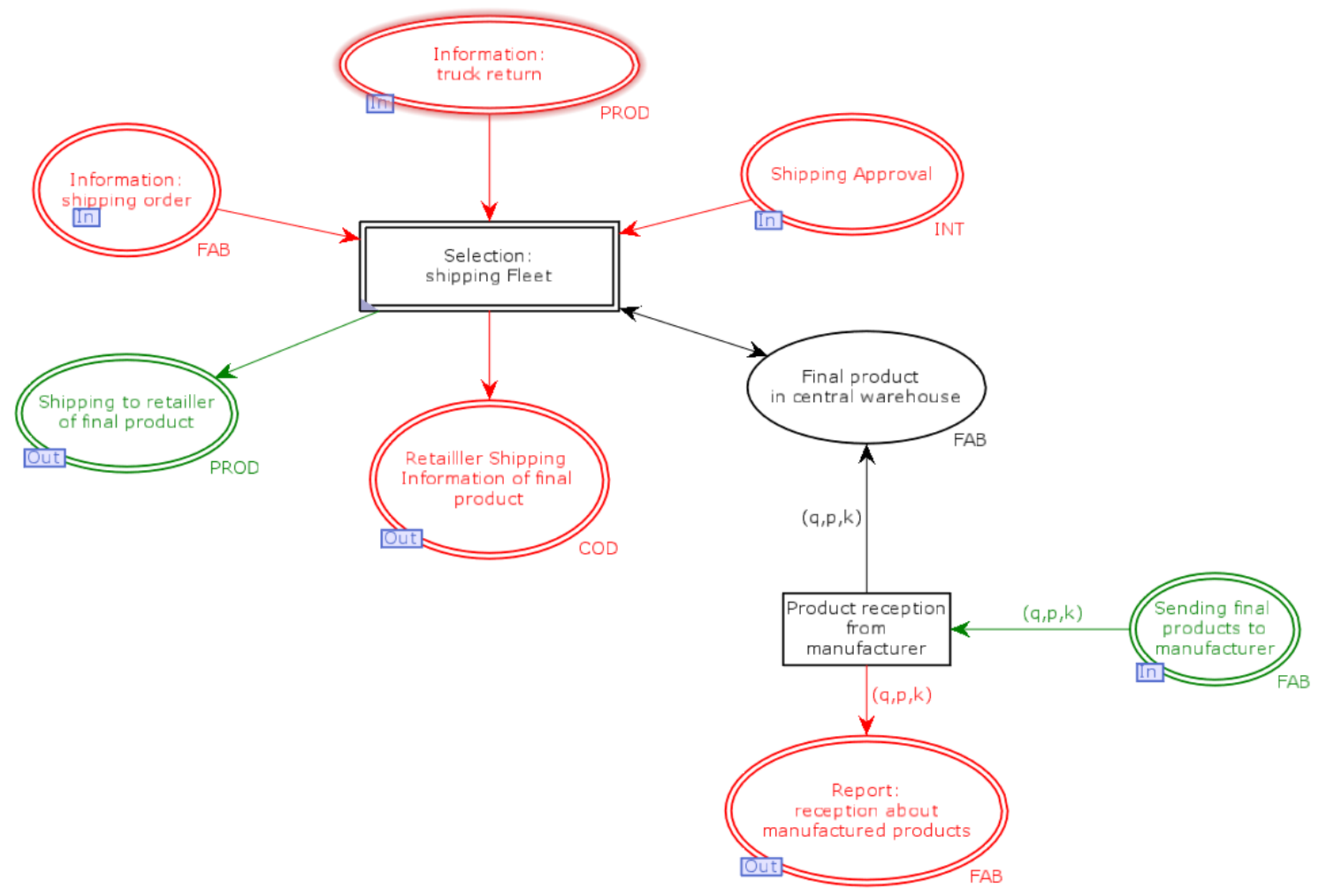

Figure 13: Logistic Operator agent network

CS information manager, it interacts with all the links except the external customer. Its main function is to articulate and keep information flows updated. Its participation begins when the "Retailer" orders a production, this is represented by a mark in the place "Production order Request", which activates the transition "Prioritize orders according to production criteria", in charge of prioritizing orders according to their arrival order and the estimated manufacturing times of each of the products. Next, an order number is assigned, represented by a marking in "Generator: manufacture production order", in turn this information returns to the transition "Prioritize orders according to production criteria", which simultaneously activates the states "Orders in production", "Information: production order", "Information: delivery order" and "Confirmation: Time remaining delivery"; within the CS this represents the action of informing the links "Manufacturing", "Suppliers", "Logistic Operator" and "Retailer" that a new batch is going to start to be manufactured, and the update in real time of this information as a new event is generated for a certain production order.

The integrating agent, in addition to informing the states of the processes, is also in charge of coordinating, presenting reports and authorizing the execution of production orders, request and reception of MP, product dispatch and inventory update.

Transition J (Figure 16) corresponds to a hierarchical transition, which is in charge of managing the information related to both the generation and the sending of reports. For this, the representation in CPN has six states "Confirmation: Time remaining delivery", "Confirmation: 


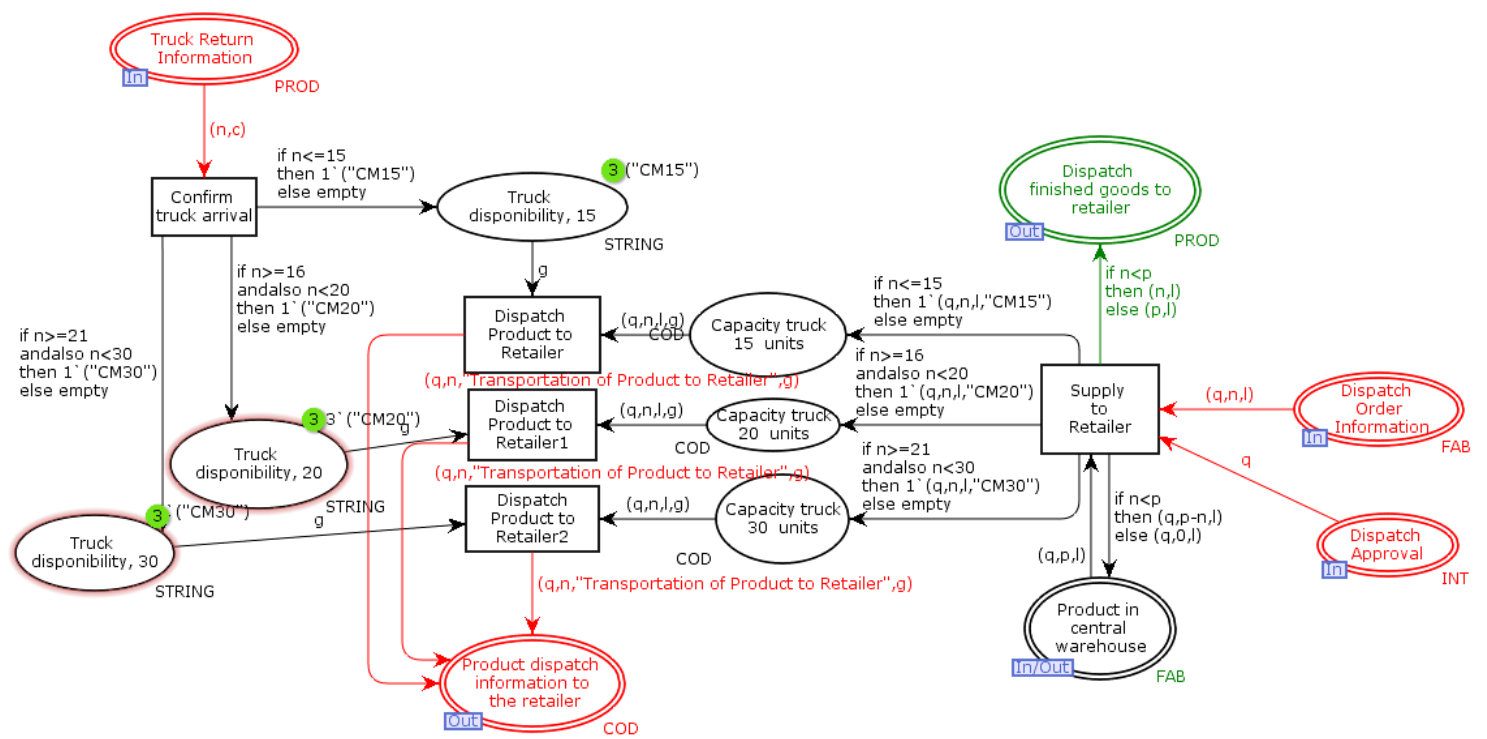

Figure 14: Logistic Operator agent subnetwork

product delivery to the retailer", "Confirmation: Production status", "Information: truck return", "Report about production" and "Information: products delivery to the retailer ", which according to the process where the production order is found, are received in this transition, then compared with pre-established production states and sent to the link of the SC that requires this information.

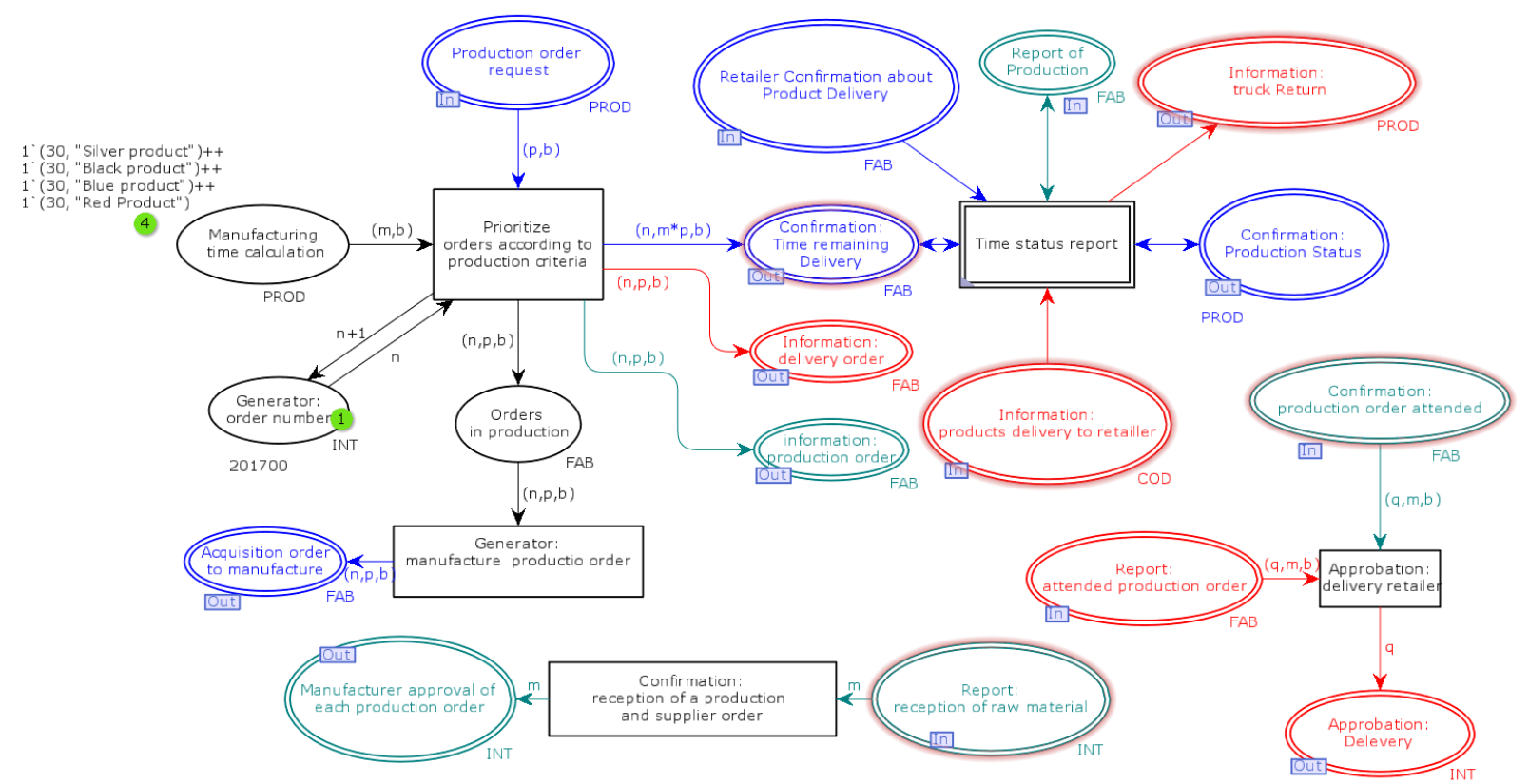

Figure 15: Integrative agent network 


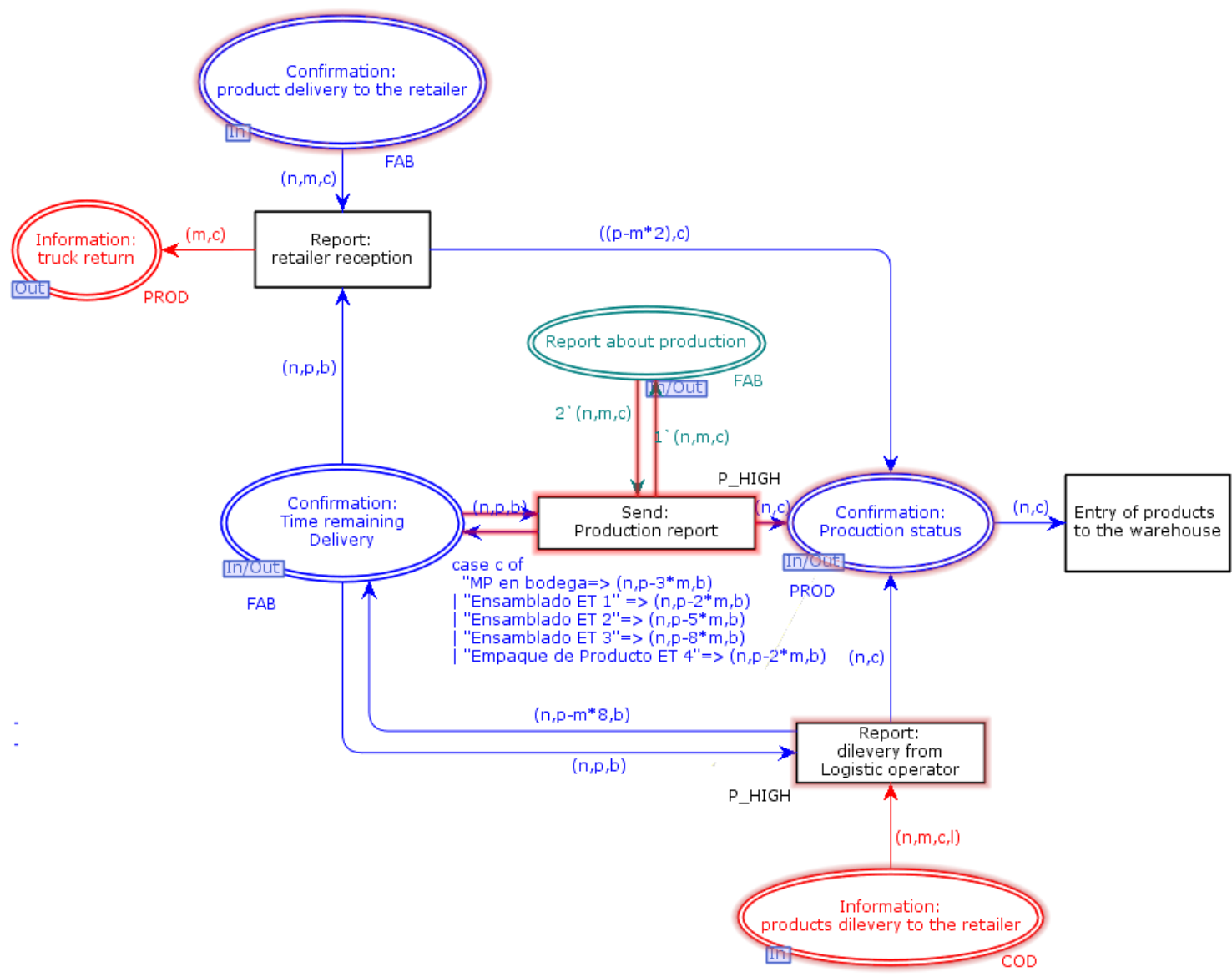

Figure 16: Integrative agent subnet

\subsection{Validation of the Proposed Architecture Model}

The model validation was carried out using simulation, considering qualitative and quantitative aspects.

6.5.1. 6.5.1. Qualitative Validation Scenarios Table 6 shows the initial operational conditions of the validation scenarios for the two-differentiating links of the SBPA SC.

\begin{tabular}{ccc}
\hline SC Links & Typical SC model & Proposed SC model \\
\hline LOA & $\begin{array}{c}\text { - On this case a logistic operator doesn't exist, but a } \\
\text { product transporter (from manufacturer warehouse } \\
\text { to the retailer) } \\
\text { - Load limitations are not considered neither the } \\
\text { trucks trips }\end{array}$ & $\begin{array}{c}\text { - It is the warehouse manufacture administrator } \\
\text { - In charge of transport dispatch and deliveries } \\
\text { to the retailer }\end{array}$ \\
\hline IA & $\begin{array}{c}\text { - Integrative agent is nonexistent, but instead a } \\
\text { person to perform the communication is assigned to } \\
\text { replace it }\end{array}$ & $\begin{array}{c}\text { It is an information administrator, in charge of } \\
\text { receiving, process, and sending signals } \\
\text { generated by their SC links to every link where } \\
\text { is needed except the external customer link }\end{array}$ \\
\hline
\end{tabular}

Table 6: Initial condition of every link 
6.5.2. 6.5.2. Qualitative Validation Analysis and Results It was verified if the model fulfilled with the SC activities, otherwise, the model was adjusted to accomplish it. Activities were taken into consideration, such as: raw material supply, product fabrication, finished product storage, production report, sale services. In the proposed model, the same activities as the current model where validated.

The proposed model compared to the current model integrates information technologies to the SC operation, they allow to the links give one part of their self-sufficiency to an integrative agent, which manages SC according to the market needs. The management include: inventory limitation by mean of a pull operation, upgrading, processing and distribution of the information and operative decision taking based on the state of the global SC.

6.5.3. 6.5.3. Quantitative Validation Scenarios The simulation scenarios were defined based on a problem map structure (Figure 6) for both models. In addition, it was verified that the proposed model meets the requirements of each SC link based on the architecture and inherent properties of multi-agent systems.

The simulated scenarios are considered for the typical and proposed system structure, as follows:

- Typical SBPA SC: It is simulated without any modification.

- Proposed SBPA SC: The CS is simulated by modifying the values of the three scenario definition parameters set above in the problem map: production rate, product mobilization from manufacturer to retailer and communication level in the process, setting seven scenarios to evaluation based on the results obtained for the system performance indicators, also set in the problem map.

The scenarios simulated are:

- Scenario 0. Current SC modeling: This scenario considers the SC typical without any modification on its links.

- Scenario 1. Modification of production rate (PR): this scenario establishes a minimum number of normalized units per time unit to produce in function of the demand.

- Scenario 2. Product mobilization from manufacturer to retailer: this scenario establishes the service change of load transport by the implementation of the logistic operator agent that besides transporting commodities, manages manufacturer inventory and SC logistic.

- Scenario 3. Effect of the communication level in the process: To model this scenario, a new link (Integrative Agent) was implemented, which articulates the other links (with the exception of the External Customer) of the SC, through the management of the bi-directional flows of information generated from the knowledge of the inventory statements in each link and the availability of logistics resources.

- Scenario 4. Joint effect of Scenario 1 and 2.

- Scenario 5. Joint effect of Scenario 1 and 3.

- Scenario 6. Joint effect of modification on Scenario 2 and 3.

- Scenario 7. Joint effect of modification on Scenario 1, 2 and 3.

6.5.4. Quantitative Validation Results and Analysis On Table 7 the results of the defined scenarios simulation are shown, for all of them a simulation of 50 production orders was established. In the scenario 0 was verified that the model represents the real SBPA SC when simulated. Table 6 shows the results obtained from the evaluated scenarios. Scenario that modifies just the production rate (Scenario 1) does not contribute remarkable improvements 


\begin{tabular}{lccccccccc}
\hline \multirow{2}{*}{ Scenario } & Modified Attributes & \multicolumn{2}{c}{ SL } & \multicolumn{2}{c}{ PTPSC } & \multicolumn{2}{c}{ CTCL } & Safery Inventory & $A I$ \\
\cline { 3 - 11 } & & Qty & $\%$ & Hours & $\%$ & Frequency & $\%$ & Qty & Units \\
& & & & & & & & & \\
\hline Typical & Typical & 41 & 81,34 & 8 & Ref & 1 & Ref & 71 & 100 \\
\hline 1 & PR & 42 & 84,32 & 7.5 & 6,25 & 1 & - & 71 & 100 \\
\hline 2 & MPMR & 43 & 86,64 & 7.5 & 6,25 & 1 & - & 70 & 100 \\
\hline 3 & CLP & 44 & 87,03 & 6.79 & 15,13 & Necessary & 50 & 60 & 80 \\
\hline 4 & PR, MPMR & 45 & 90.05 & 7.08 & 11,50 & 1 & - & 70 & 70 \\
\hline 5 & PR, CLP & 47 & 92,79 & 6.43 & 19,63 & Necessary & 50 & 60 & 60 \\
\hline 6 & MPMR, CLP & 46 & 91,92 & 6.11 & 23,63 & Necessary & 83.33 & 40 & 40 \\
\hline 7 & PR, MPMR, CLP & 49 & 98,07 & 5.71 & 28,63 & Necessary & 83.33 & 40 & 40 \\
\hline
\end{tabular}

Table 7: Improvement results obtained from the evaluated scenarios

to the SC system. The scenarios that propose to add a modification of the mobilization and communication attributes as a measure to introduce intelligent agents (scenario 2 and 3), improve the service level and reduce the products permanency time on the manufacturer link, but acting separately they don't offer greater improvements on the SBPA SCM performance indicators. The scenario that proposes to carry out communication follow-ups throughout the process (Scenario 6), offers relative improvements in SBPA SC performance indicators compared to immediately preceding scenarios. Finally, Scenario 7 evaluating result, defined from the combined modification of the three scenario definition parameters, generates improvements in practically all indicators in the SC beginning with the service level (98.07\%).

\section{Conclusions}

Considering the technological advances and the challenges of SC, in this research a multi-agent architecture for a SC integrating a MA approach using $\mathrm{CPN}$, that contributes to the sustainability of the SC performance in the digital era was proposed. to do this, taking advantage of the structural flexibility of a training laboratory in an educational institution in Colombia, an analogy was performed with a typical supply chain to formulate the case study, then the benefits of converting it to a distributed system architecture were evaluated its entirety. The proposed model contained two agents, a manufacturer and a logistics operator. This architecture is deliberative (goal-oriented) due to i) the way the agent plans to achieve its goals based on its perception of the environment, and ii) its plans could be modified if the surrounding environment changes. The multi-agent structure is also reactive because the actions taken depend on the inputs received. These were arguments for selecting CPN as a modeling approach in the SC redesign roadmap.

The results allowed proving the strengths of the proposed model based on an interrelation between the inventory management and the information management (product request, processing information, SC integration, production order generation, link update information). The Logistic Operator Agent manages globally the manufacturer warehouse, finished product dispatch and transport considering the features of assigned resources. The results proved that a distributed architecture of SC with a multi-agent structure favors the performance indicators, for example reduces idle times among other aspects.

By means of the quantitative validation it was identified that improving the production rate, the mobilization of products from manufacturing to retailer and the communication level in the process, an improvement of $69.42 \%$ compared to the typical SC was achieved. This value reflected an increment service level of $14.73 \%$, while the permanency time of the product in the SC decreased 54.63\%. The connection time in communication among links improved on 83.33\% above the current SC communication architecture. Related to the Average Inventory, 
storage savings on the different SC links had $43.66 \%$ compared to the current SC. By simulating the isolated scenarios 1,2 and 3, indicates that scenario 3, where the Integrating Agent is integrated, has a contribution that makes the system improve overall by $42.47 \%$. When combining attributes, its improvement was significant, as shown when the two agents, Logistic operator and Integrative agent are integrated to the model, in scenario 6, the service level improved to $91.92 \%$, which represents an increase of $10.58 \%$ improvement over the scenario showing typical SC.

These results allowed us to answer the research question posed and validate the advances in the field of the use of formal modeling tools, such as Colored Petri Nets. In this case, it was applied to the design of a supply chain, conceived as a system distributed and based on MAS. Finally, it is expected that the results will encourage industrial, logistics and commercial organizations to integrate a supply chain considering the MAS in resource management. These intelligent structures allow an agile response to variations in the productive environment, a characteristic recommended in emerging economies, such as the national one, where supply chains are especially vulnerable. As a future work, extended modeling is projected by integrating advances of tics such as Data Analytics, Big Data and Machine Learning, oriented to improve performance and sustainability levels.

\section{Acknowledgments}

Thanks to the National Learning Service (SENA, Valle del Cauca section, Colombia) and Universidad del Valle, Cali, Colombia, for their support on making this project possible.

\section{Declaration of Conflicting Interests}

The author declared no potential conflicts of interest with respect to the research, authorship, and/or publication of this article.

\section{References}

[1] Z. M. Bi, S. Y. Lang, W. Shen, and L. Wang, "Reconfigurable manufacturing systems: the state of the art," International journal of production research, vol. 46, no. 4, pp. 967-992, 2008.

[2] X. Qiu, L. Cao, P. Li, and L. Zhao, "Architecture approach for ict supply chain integrity," in ICT 2013, pp. 1-5, IEEE, 2013.

[3] C. Bravo, J. Aguilar-Castro, A. Ríos, J. Aguilar-Martin, and F. Rivas, "Arquitectura basada en inteligencia artificial distribuida para la gerencia integrada de producción industrial," Revista Iberoamericana de Automática e Informática Industrial RIAI, vol. 8, no. 4, pp. 405-417, 2011.

[4] F. B. Hmida, W. L. Chaari, R. Dupas, and A. Séguy, "Evaluation of communication in multiagent systems for supply chain planning and control," in 2014 IEEE 26th International Conference on Tools with Artificial Intelligence, pp. 408-412, IEEE, 2014.

[5] J. Ansari, A. Gholami, and A. Kazemi, "Holonic structure: a state-of-the-art control architecture based on multi-agent systems for optimal reactive power dispatch in smart grids," IET Generation, Transmission \& Distribution, vol. 9, no. 14, pp. 1922-1934, 2015.

[6] O. Lengerke, "Arquitectura empresarial, el camino hacia un gobierno integrado," Cio@ Gov, vol. 2, 2013.

[7] G. J. Hahn, "Industry 4.0: a supply chain innovation perspective," International Journal of Production Research, vol. 58, no. 5, pp. 1425-1441, 2020.

[8] E. Oztemel and S. Gursev, "Literature review of industry 4.0 and related technologies," Journal of Intelligent Manufacturing, vol. 31, no. 1, pp. 127-182, 2020.

[9] R. C. Basole, M. A. Bellamy, H. Park, and J. Putrevu, "Computational analysis and visualization of global supply network risks," IEEE Transactions on Industrial Informatics, vol. 12, no. 3, pp. 1206-1213, 2016.

[10] M. A. Bellamy, S. Ghosh, and M. Hora, "The influence of supply network structure on firm innovation," Journal of Operations Management, vol. 32, no. 6, pp. 357-373, 2014.

[11] S. Yuvaraj and M. Sangeetha, "Smart supply chain management using internet of things (iot) and low power wireless communication systems," in 2016 international conference on wireless communications, signal processing and networking (WiSPNET), pp. 555-558, IEEE, 2016.

[12] G. Weiss, Multiagent systems: a modern approach to distributed artificial intelligence. MIT press, 1999. 
[13] M. Wooldridge and N. R. Jennings, "Intelligent agents: Theory and practice," The knowledge engineering review, vol. 10, no. 2, pp. 115-152, 1995.

[14] S. J. Russell and P. Norvig, Inteligencia Artificial: un enfoque moderno. No. 04; Q335, R8y 2004., 2004.

[15] Z. Tang and Y. Pan, "Agent-based supply chain management modeling and simulation," in 2014 IEEE International Conference on Information and Automation (ICIA), pp. 1255-1259, IEEE, 2014.

[16] J. Aguilar, F. Rivas, M. Cerrada, J. Chacal, and C. Bravo, "Sistemas multiagentes para la planificación y manejo de los factores de producción en automatización," Ciencia e Ingeniería, vol. 31, no. 1, pp. 13-23, 2009.

[17] D. W. Payton, D. Keirsey, D. M. Kimble, J. Krozel, and J. K. Rosenblatt, "Do whatever works: A robust approach to fault-tolerant autonomous control," Applied Intelligence, vol. 2, no. 3, pp. 225-250, 1992.

[18] C.-P. Lin, "A petri-net modeling tool and its application on intelligent network," in 2013 7th Asia Modelling Symposium, pp. 93-98, IEEE, 2013.

[19] M. Tadao, "Petri nets: properties, analysis and applications," Proceedings of the IEEE, vol. 77, no. 4, 1990.

[20] L. D. Murillo-Soto, "Simulación de un sistema de manufactura flexible con redes de petri coloreadas," Revista Tecnología en Marcha, vol. 23, no. 1, pp. ág-47, 2010.

[21] C. Petri, Kommunikation mit Automaten (English translation: Technical Report RADC-TR-65-37r). PhD thesis, PhD Thesis, University of Bonn (Eng: Vol.], Suppl 1, AppliedData Research ..., 1962.

[22] K. Jensen, Coloured Petri Nets: Basic Concepts, Analysis Methods and Practical Use. Volume 1. Springer Science \& Business Media, 2013.

[23] K. Jensen and L. M. Kristensen, Coloured Petri nets: modelling and validation of concurrent systems. Springer Science \& Business Media, 2009.

[24] W. Van der Aalst, "Putting high-level petri nets to work in industry," Computers in Industry, vol. 25, no. 1, pp. 45-54, 1994.

[25] F. B. Hmida, W. L. Chaari, R. Dupas, and A. Séguy, "Evaluation of communication in multiagent systems for supply chain planning and control," in 2014 IEEE 26th International Conference on Tools with Artificial Intelligence, pp. 408-412, IEEE, 2014.

[26] Y. Shoham, "Agent-oriented programming," Artificial intelligence, vol. 60, no. 1, pp. 51-92, 1993.

[27] K. Pal and B. Karakostas, "A multi agent-based service framework for supply chain management," Procedia Computer Science, vol. 32, pp. 53-60, 2014.

[28] C. R. Jaimez-González and W. A. Luna-Ramírez, "An agent-based architecture for supply chain management," in 2013 IEEE Eleventh International Symposium on Autonomous Decentralized Systems (ISADS), pp. 1-6, IEEE, 2013.

[29] J. Zhao and H. Zhao, "Design of prototype system for multi-agent supply chain information sharing benefit distribution management," Information Systems and E-Business Management, vol. 18, no. 4, pp. 581-602, 2020.

[30] L. Perera and A. Karunananda, "Using a multi-agent system for supply chain management," Complex Systems: Fundamentals \&5 Applications, vol. 90, p. 263, 2016.

[31] A. Fiedler, D. Sackmann, and H.-D. Haasis, "A literature review on the state of the art of multi-agent systems in supply chain management," Logistics Management, pp. 62-74, 2019.

[32] M. Mes and B. Gerrits, "Multi-agent systems," in Operations, Logistics and Supply Chain Management, pp. 611-636, Springer, 2019.

[33] R. Domínguez Cañizares and S. Cannella, "Insights on multi-agent systems applications for supply chain management," 2020.

[34] M. Herrera, M. Pérez-Hernández, A. Kumar Parlikad, and J. Izquierdo, "Multi-agent systems and complex networks: Review and applications in systems engineering," Processes, vol. 8, no. 3, p. 312, 2020.

[35] M. Falco and G. Robiolo, "A systematic literature review in multi-agent systems: Patterns and trends," in 2019 XLV Latin American Computing Conference (CLEI), pp. 1-10, IEEE, 2019.

[36] D. Ho, A. Kumar, and N. Shiwakoti, "A literature review of supply chain collaboration mechanisms and their impact on performance," Engineering Management Journal, vol. 31, no. 1, pp. 47-68, 2019.

[37] F. E. Ettahiri and M. Elmaallam, "The contribution of knowledge engineering in supply chain: A literature review," in International Conference on Information Technology 85 Systems, pp. 21-31, Springer, 2019.

[38] M. Abdirad and K. Krishnan, "Industry 4.0 in logistics and supply chain management: A systematic literature review," Engineering Management Journal, pp. 1-15, 2020.

[39] J. J. Palop, L. Mucke, and E. D. Roberson, "Quantifying biomarkers of cognitive dysfunction and neuronal network hyperexcitability in mouse models of alzheimer's disease: depletion of calcium-dependent proteins and inhibitory hippocampal remodeling," in Alzheimer's Disease and Frontotemporal Dementia, pp. 245-262, Springer, 2010.

[40] Q. Bai, M. Zhang, and H. Zhang, "A colored petri net based strategy for multi-agent scheduling," in Rational, Robust, and Secure Negotiation Mechanisms in Multi-Agent Systems (RRS'05), pp. 3-10, IEEE, 2005. 
[41] S. Aggarwal and H. Pathak, "Modelling of hierarchical location management schemes to locate mobile multi agents using colored petri net," in 2015 International Conference on Advances in Computer Engineering and Applications, pp. 821-825, IEEE, 2015.

[42] F. Huan and W. Lili, "Colored petri net based multi-agents dynamic task allocation modeling and analysis," in The 2nd International Conference on Information Science and Engineering, pp. 1080-1083, IEEE, 2010.

[43] F. Moutinho, J. Ribeiro, and L. Gomes, "Distributed controllers modeling through petri nets with multi-asynchronous-channels," in 2015 IEEE International Conference on Industrial Technology (ICIT), pp. 1564-1569, IEEE, 2015.

[44] J. Aelker, T. Bauernhansl, and H. Ehm, "Managing complexity in supply chains: A discussion of current approaches on the example of the semiconductor industry," Procedia CIRP, vol. 7, pp. 79-84, 2013.

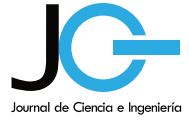

